\title{
Development of a model for the prediction of the fuel consumption and nitrogen oxides emission trade-off for large ships
}

\author{
Larsen, Ulrik; Pierobon, Leonardo; Baldi, Francesco ; Haglind, Fredrik; Ivarsson, Anders
}

Published in:

Energy

Link to article, DOI:

10.1016/j.energy.2014.12.009

Publication date:

2015

Link back to DTU Orbit

Citation (APA):

Larsen, U., Pierobon, L., Baldi, F., Haglind, F., \& Ivarsson, A. (2015). Development of a model for the prediction of the fuel consumption and nitrogen oxides emission trade-off for large ships. Energy, 80, 545-555.

https://doi.org/10.1016/j.energy.2014.12.009

\section{General rights}

Copyright and moral rights for the publications made accessible in the public portal are retained by the authors and/or other copyright owners and it is a condition of accessing publications that users recognise and abide by the legal requirements associated with these rights.

- Users may download and print one copy of any publication from the public portal for the purpose of private study or research.

- You may not further distribute the material or use it for any profit-making activity or commercial gain

- You may freely distribute the URL identifying the publication in the public portal 


\title{
Development of a model for the prediction of the fuel consumption and nitrogen oxides emission trade-off for large ships
}

\author{
Ulrik Larsen $^{\mathrm{b}, *}$, Leonardo Pierobon ${ }^{\mathrm{a}}$, Francesco Baldi ${ }^{\mathrm{b}}$, Fredrik Haglind $^{\mathrm{a}}$, Anders Ivarsson ${ }^{\mathrm{a}}$ \\ ${ }^{a}$ Section of Thermal Energy, Department of Mechanical Engineering, Technical University of Denmark, \\ Building 403, Nils Koppels Allé, 2800 Kgs. Lyngby, Denmark \\ ${ }^{b}$ Chalmers University of Technology, Maritime Operations, SE-412 96 Gothenburg, Sweden
}

\begin{abstract}
The international regulations on fuel efficiency and NOx emissions of commercial ships motivate the investigation of new system layouts, which can comply with the regulations. In combustion engines, measures to reduce the fuel consumption often lead to increased NOx emissions and careful consideration of this trade-off mechanism is required in the design of marine propulsion systems. This study investigates five different configurations of two-stroke diesel-based machinery systems for large ships and their influence on the mentioned trade-off. Numerical models of a low-speed two-stroke diesel engine, turbochargers and an organic Rankine cycle, are used for the optimisation of the NOx and fuel consumption at design and part-load conditions, using a multi-objective genetic algorithm. Moreover, the effects of engine tuning and exhaust gas recirculation are investigated. The results suggest that increased system complexity can lead to lower fuel consumption and NOx. Fuel consumption reductions of up to $9 \%$ with a $6.5 \%$ NOx reduction were achieved using a hybrid turbocharger and organic Rankine cycle waste heat recovery system.
\end{abstract}

Keywords: Organic Rankine cycle, Two-stroke low-speed diesel engine, Part-load performance optimisation, Waste heat recovery, NOx emissions

\section{Introduction}

The International Maritime Organisation (IMO) has set global NOx emission limits which require a $15 \%$ reduction for new built ships powered by low-speed engines. This modest reduction can be achieved in various ways, simplest by adjusting the engine parameters, e.g., the valve and

${ }^{*}$ Principal corresponding author. Tel.: +4553250303

Email address: ulrik.larsen@chalmers.se (Ulrik Larsen) 
injection timings. However, it is well known that such measures used to reduce the NOx lead to increases in the brake specific fuel oil consumption (SFOC) and vice versa, thus constituting a trade-off of key importance in the optimisation of the marine propulsion plant.

Exhaust gas recirculation (EGR) is well known to strongly reduce NOx emissions, and EGR can therefore affect the SFOC-NOx trade-off mechanism and lead to reduced SFOC while complying with NOx regulations [1]. Waste heat recovery (WHR) systems, such as steam Rankine cycles and organic Rankine cycles (ORC), produce power from the exhaust gasses and possibly other heat sources from the main engine, without causing NOx emissions. This power can be converted to propeller shaft power using a shaft motor and thus simultaneously reduce the SFOC and NOx emissions (both measured in $\mathrm{g} / \mathrm{kWh}$ ).

Since the IMO NOx emission limits are defined as a weighted average of four engine loads, 100, 75, 50 and 25\% (ISO 8178), and since ship engines run at part-loads a significant part of the time [2], the analysis of the part-load performance of both engine and WHR system is important. Moreover, it is reported [3], that the marine low-speed engine is operated with a reduced thermal efficiency when it is part of a combined cycle with a WHR system, compared to when running in a stand-alone application; for the benefit of the WHR system and combined cycle performance.

Studies of marine WHR systems are present in the literature. A review with particular focus on WHR systems for marine two-stroke engines was recently presented by Shu et al. [4]. Choi et al. [5] presented a thermodynamic analysis of a dual-loop WHR system for exhaust gas heat recovery on a large two-stroke low-speed diesel engine. The work considers an actual operational profile of the system and reports a $6 \%$ SFOC reduction due to the addition of the WHR system. Theotokatos et al. [6] analysed the performance of a single pressure steam Rankine WHR system on a two-stroke marine engine, considering part-load operation and the implementation of a more advanced WHR system type was recommended. In two detailed studies, Dimopoulus et al. [7, 8] reported on the design and thermo-economical optimisation of a dual-pressure steam cycle and power turbine WHR system. Multiple parameters, among those the heat exchanger geometrical dimensions, were optimised simultaneously, while considering a relevant operational profile. Dimopoulus et al. [7, 8] concluded that the system is cost-effective and that the overall system efficiency can reach $51.3 \%$. Hountalas et al. [9] presented optimisations of an ORC utilising exhaust gas and charge air heat on a large two-stroke engine running at different loads and concluded that utilising the charge air 


\section{Nomenclature}

\section{Acronyms}

ABDC After bottom dead center

CAD Crank angle degrees

EGR Exhaust gas recirculation

EOI End of injection

EVC Exhaust valve closing

HTC Hybrid turbocharger

IMO The International Maritime Organisation

MCR Maximum continuous rating

ME Main engine

NPV Net present value

ORC Organic Rankine cycle

PT Power turbine

SFOC Specific fuel oil consumption

SOI Start of injection

T/C Turbocharger

WHR Waste heat recovery

\section{Greek Symbols}

$\Delta$ Difference (-)

$\eta$ Efficiency (-)

\section{Symbols}

$\dot{m}$ Mass flow rate $(\mathrm{kg} / \mathrm{s})$

$\dot{V}$ Volumetric flow rate $\left(\mathrm{m}^{3} / \mathrm{s}\right)$

$\bar{U}$ Overall heat transfer coefficient $\left(W / m^{2} * K\right)$

$\theta$ Combustion duration (rad)
$A$ Heat transfer area $\left(m^{2}\right)$

$C_{T}$ Turbine constant $\left(k g K^{0.5} s^{-1} b a r^{-1}\right)$

$F$ Electric loss (-)

$h$ Enthalpy $(k J / k g)$

$l$ Load (-)

$M$ Shape parameter (-)

$P$ Pressure $($ Bar $)$

$Q$ Heat $(k J)$

$T$ Temperature $(K)$

\section{Subscripts}

a Air

cr Critical point

cu Copper

d Design point

dc Diffusion controlled combustion

f Fuel

i Inlet

o Outlet

p Pump

pc Pre-mixed combustion

pp Pinch point

s Isentropic

sc Scavenging

w Waste heat recovery system inlet 
heat may not be feasible when using a recuperated ORC. Recently, Guan et al. [10] presented an analytical study of the part-load performance of different main engine and turbocharger $(\mathrm{T} / \mathrm{C})$ configurations useful for low-load operation. A novel methodology for the modelling of the compressor low-speed region was also proposed in this work.

Numerous studies of the diesel engine and ORC combined cycle used in other applications exist. In a recent study, Yu et al. [11] investigated the implementation of an ORC WHR system for a generator diesel engine running at five different load points. The ORC utilised both engine jacket water heat and exhaust gas heat. The study reported a $6 \%$ improvement of the system thermal efficiency caused by the addition of an ORC bottoming cycle.

The novel academic contributions of the present work are summarised as follows. In previous work involving two of the present authors [12], the two-stroke engine model used in the present paper was validated with regards to key engine tuning parameters. The present work builds upon this previous work by studying the potential of engine tuning to enhance the combined cycle performance. Thus, an investigation aiming at quantifying the part-load weighted SFOC-NOx trade-off is presented along with methodologies for the optimisation of the performance of five different system configurations based on the two-stroke marine diesel engine. The configurations include a power turbine, an EGR system, an ORC WHR system and a hybrid T/C and ORC system. The optimisation efforts include the main engine tuning parameters, namely, the injection and valve timings, air and fuel mass flow rates and the scavenging pressures, which are optimised simultaneously with the WHR system operating parameters. In the above mentioned studies, and in other studies that can be found in the open literature concerning marine two-stroke engine systems, the aspect of main engine tuning has not been considered from a system perspective to the detail presented in this work. Moreover, investigations of the SFOC and NOx trade-off, whilst considering the part-load behaviour of all system components, have, to the best knowledge of the authors, not been presented for the mentioned type of combined cycle systems. Finally, studies that include the innovative combination of using a hybrid type turbocharger together with an ORC for WHR on the two-stroke engine have also not been presented before.

Section 2 presents an outline of the modelling approach and the optimisation methodology. Validation of the engine model is presented in Sec. 3. Results are presented in Sec. 4, followed by a discussion of the results and implications of the present work in Sec. 5. 


\section{Methodology}

\subsection{System configurations}

Five system configurations are investigated individually with regards to the SFOC-NOx tradeoff: 1) The baseline configuration is a diesel engine with three $\mathrm{T} / \mathrm{Cs}$ and an auxiliary blower (AB), 2) an exhaust gas power turbine (PT) is added to the baseline system, 3) the baseline with an EGR system, 4) the baseline with an ORC exhaust WHR system, and 5) the diesel engine with three hybrid T/Cs and an ORC exhaust WHR system and no AB.

The simplified system layout of configurations 1-3 is outlined in Fig. 1. Each T/C consists of a radial flow compressor $(\mathrm{C})$ and a single-stage axial-flow turbine $(\mathrm{T})$. A throttle valve is used to bypass the amount of exhaust gas which is in excess in relation to powering of the T/Cs. An AB is used to provide the needed air flow and pressure at $25 \%$ load. Ambient air enters the compressors and is cooled in the air cooler before it enters the scavenge air receiver and finally the engine. The engine exhaust enters the exhaust receiver from where it can be directed to the EGR system, the power turbine, the T/Cs and the bypass. In the PT configuration (2), the mentioned excess exhaust gas is expanded to produce electrical power via a generator $(G)$, which is then converted back into propulsion power using a propeller shaft motor (SM).

In the EGR configuration (3), $10 \%$ of the exhaust is recirculated through an EGR cooler (EC) and an EGR blower (EB) is used to provide the needed flow and pressure. This EGR arrangement is directly inspired by the work on marine EGR systems presented by Kaltoft et al. [1] and not all the components are depicted, most importantly the exhaust scrubbers, a water mist catcher, valves and mixing chambers, which are considered to be of minor influence to the results.

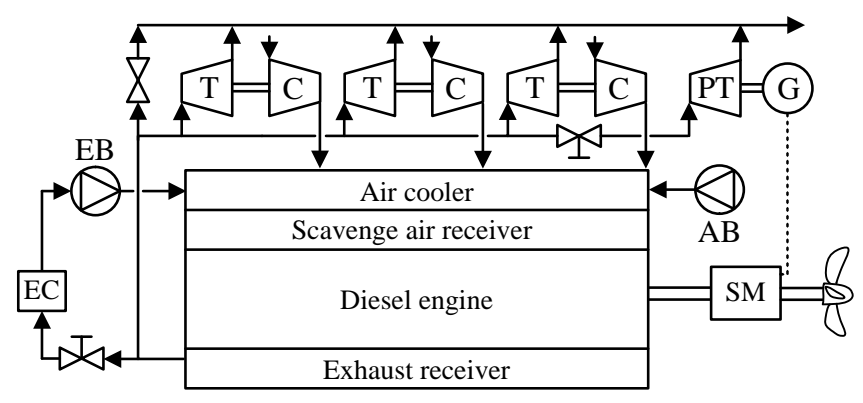

Figure 1: Sketch of configurations 1-3

Figure 2 illustrates a configuration of the main engine fitted with hybrid T/Cs and an ORC for 
exhaust gas heat recovery (find a description of the hybrid T/C in Sec. 2.3.1). Electrical power produced by the ORC and the hybrid T/Cs is converted into shaft power using the shaft motor.

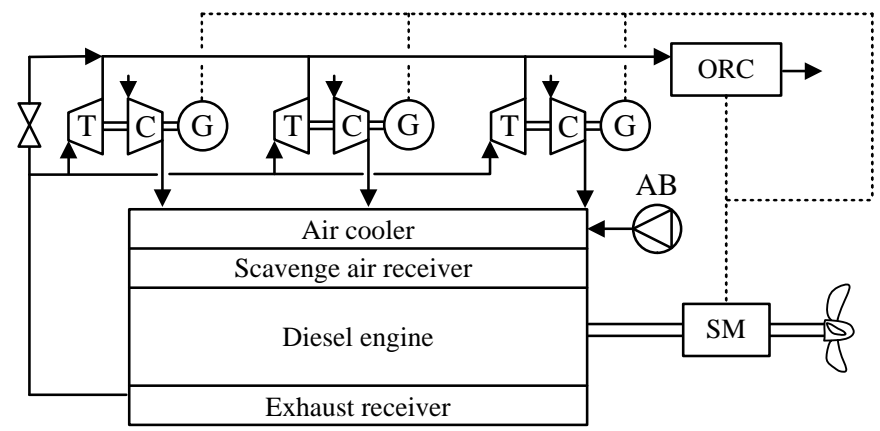

Figure 2: Sketch of configurations 4 and 5

Figure 3 illustrates the ORC configuration where the working fluid first enters a pump and is then preheated in a recuperator. The fluid is then further preheated, evaporated and finally superheated using the exhaust gas. The fluid then expands in a turbine while producing power via a generator, before the remaining heat is transferred to the working fluid again and is finally condensed in the condenser.

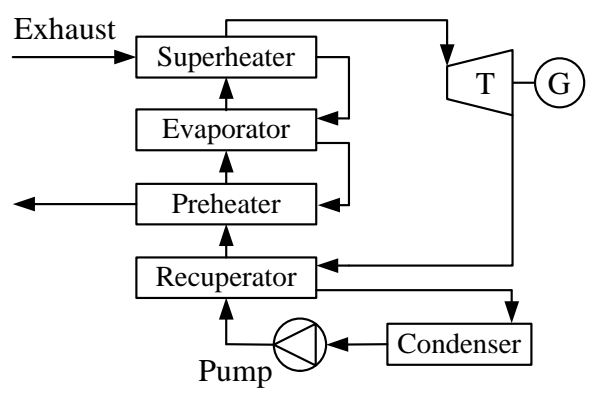

Figure 3: Sketch of the ORC process

\subsection{The diesel engine model}

Scappin et al. [12] provide a detailed description of the marine low-speed two-stroke diesel engine model applied in the present work. The same work presents a validation of the model with respect to the SFOC and NOx response, due to variations in the scavenge, compression and maximum pressures. Since that paper was published, improvements to the model were made as described below. 
Briefly described, the model is a zero-dimensional type implemented with a two-zone combustion sub-model, implying that there is a combustion zone wherein reactions occur and an inactive zone containing the remaining cylinder gasses. A double Wiebe function [13] is used to model the heat release, the Woschni correlation [14] is used to predict heat transfer and the NOx emissions are predicted using the extended Zeldovich mechanisms [15]. EGR is modelled by adding the specified amount of exhaust gas to the intake air, and the resulting exhaust gas composition is found by iteration.

Using the ideal gas equation for modelling high pressure engines may result in under-prediction of compression and maximum pressures for a given cylinder geometry and valve timing $[16,17]$. The Redlich-Kwong equation of state was therefore implemented as according to the work of Danov et al. [18]. The ignition delay sub-model was also updated to make the result better fit the observations made by Poulsen [19] of the combustion in the same engine type. After the investigation of several models, the best agreement was found when using a model by Hardenberg and Hase [20]. A friction model by Chen and Flynn [21] was added for a more correct estimation of the engine brake power output. Good agreement was found when using the Chen and Flynn model and to a lesser degree with the friction model proposed by Winterbone [22].

Goldsworthy [23] pointed to the importance of nitrous oxide reactions in addition to the reactions included in the very commonly used extended Zeldovich mechanism, when modelling the NOx formation in marine engines. Other studies confirm this, notably the work of Kilpinen [24]. Consequently, these reactions were added to the model as in accordance with Kilpinen [24].

\subsubsection{Calibration}

Models of a MAN 7L70MC type engine and a MAN 12K98ME type engine were built and calibrated for the validation of the part-load performance. The 12K98ME engine was used for optimisation in the present study, while the 7L70MC engine was used in a previous study [25]. The only available NOx emissions data found are for the 7L70MC engine, and these figures are therefore included in the present work. Both engines appear to have been tuned to comply with the IMO NOx Tier I limit of $17 \mathrm{~g} / \mathrm{kWh}$. The fuel in both cases is specified as a marine test bed fuel with a lower heating value of $42,700 \mathrm{~kJ} / \mathrm{kg}$. Table 1 presents the specifications for the two engines.

For the 7L70MC engine model, very detailed input and performance data was found in the 
Table 1: Diesel engine specifications

\begin{tabular}{rrr}
\hline Type & 12K98ME-C6 & 7L70MC-mk6 \\
Cylinders (-) & 12 & 7 \\
Bore (m) & 0.98 & 0.70 \\
Stroke (m) & 2.66 & 2.268 \\
Engine speed MCR (rpm) & 104 & 108 \\
Specified MCR (MW) & 68.52 & 19.81 \\
Turbochargers (-) & 3 & $\mathrm{~N} / \mathrm{A}$ \\
Turbochargers type (-) & High efficiency & N/A \\
Mean effective pressure (bar) & 18.2 & 17.3 \\
\hline
\end{tabular}

work of Goldsworthy [26] and through the online MAN Diesel \& Turbo engine room dimensioning tool CEAS [27]. The genetic algorithm (see Sec. 2.5) was used to calibrate the 7L70MC model with the objective of minimising the root-mean-square deviation of the relative difference between measured data and model predictions. The exhaust valve opening time and the $\alpha$ constant of the Woschni heat transfer correlation (see Scappin et al. [12]) were adjusted together with the end of injection timing (EOI), which was adjusted at the loads 25, 50, 75 and $100 \%$.

For the $12 \mathrm{~K} 98 \mathrm{ME}$ engine model, experimentally obtained heat release and pressure curves for the four loads were provided by the manufacturer. The modelled heat release was adjusted to match the measured data with the duration and shape parameters $\left(Q_{p c}, M_{p c}, \Delta \theta_{p c}\right.$ and $\left.M_{d c}\right)$ of the Wiebe heat release formula (see Scappin et al. [12]) and the injection timing. The exhaust valve opening time was adjusted to match the power outputs. This was needed because the valve opening is modelled as an instantaneous opening for simplification. All other model input data was found in unpublished documents provided by the manufacturer and via the CEAS tool [27].

The combustion event in the marine low-speed two-stroke diesel engine is dominated largely by diffusive combustion (see Fig. 5). During diffusion controlled combustion, the oxygen-fuel ratio in the reaction zone is governed by diffusion processes, and the ratio is commonly assumed to be near to stoichiometric conditions. According to the detailed experimental work and modelling efforts made by Egnell [28], the combustion reaction zone oxygen-fuel ratio can, for a given injection system, be considered constant also under operational variations. In the present calibration, the reaction zone oxygen-fuel ratio was thus adjusted in accordance with Egnell [28], to get the best match of the NOx emissions, resulting in a constant equivalence ratio $(\lambda)$ of 1.10 . 


\subsection{Turbochargers and blowers}

The T/Cs were modelled using compressor and turbine maps for a turbocharger model type (ABB A175) which is slightly smaller than the type A185, that is recommended by the manufacturer of the $12 \mathrm{~K} 98 \mathrm{ME}$ engine. The maps were provided by $\mathrm{ABB}$ and are kept confidential as to the request of $\mathrm{ABB}$. The compressor and turbine maps were scaled by applying the methodology presented by Kurzke [29], with the volumetric flow at 100\% load representing the reference point. A compressor operating line was drawn on the map to ensure maximum isentropic efficiencies for the loads 50-100\%, while maintaining a surge safety margin of $15 \%$ [30] and an even larger choke margin. The relationship between mass flow rate $(\dot{m})$, pressure in and out $\left(P_{i}\right.$ and $\left.P_{o}\right)$ and inlet temperature $\left(T_{i}\right)$ for the $\mathrm{T} / \mathrm{C}$ turbine is governed by the Stodola [31] turbine constant $\left(C_{T}\right)$ :

$$
C_{T}=\frac{\dot{m} \sqrt{T_{i}}}{\sqrt{P_{i}^{2}-P_{o}^{2}}}
$$

The thermodynamic properties of the air and exhaust gas were obtained using Refprop version 9 [32]. The power turbine and the hybrid turbines were assumed to have the same characteristics as the T/C turbines. The power consumption of the auxiliary and EGR blowers were estimated by dividing the product of the averaged volumetric flow rate and the inlet and outlet pressure difference with the efficiency (Tab. 4). A pressure drop of 0.02 bar over the EGR cooler was assumed [1].

\subsubsection{The hybrid turbocharger}

It is well known that the exhaust gas temperature from the low-speed two-stroke diesel engine is low compared to other engine types, especially at low loads. The T/C efficiency is therefore required to be relatively high in order to provide the required scavenging pressures and flows, using only the exhaust gas to drive the compressors. This has driven the development to the point where the $\mathrm{T} / \mathrm{C}$ efficiency is higher than needed at high loads.

Mitsui [33], Mitsubishi [34] and others have proposed a hybrid type T/C (HTC) which consists of a turbine and a compressor directly coupled to a high-speed electric generator/motor (see Fig. 2). At high load conditions, additional electrical power can be produced and at low loads the motor can add needed power. With this system it is claimed that the auxiliary blower can be removed as well as the power turbine, thus simplifying the system. Moreover, the hybrid $\mathrm{T} / \mathrm{C}$ provides an 
additional degree of freedom in the engine tuning because the WHR system can provide power to assist the $\mathrm{T} / \mathrm{Cs}$ at any point.

\subsection{The organic Rankine cycle}

The pump was modelled in a similar way as done by Quoilin et al. [35], but due to the larger scale of application, it was assumed to have a higher overall efficiency; the coefficients $(a, b, c$ and $d$ ) were therefore adjusted to make the pump characteristics resemble those of commercially available centrifugal pumps [36]. The pump isentropic efficiency $\left(\eta_{p}\right)$ at part-load relative to the design point efficiency $\left(\eta_{p, d}\right)$ is thus defined as a function of the volumetric flows at part-load and design point $\left(\dot{V}\right.$ and $\left.\dot{V}_{d}\right)$ :

$$
\frac{\eta_{p}}{\eta_{p, d}}=a\left(\frac{\dot{V}}{\dot{V}_{d}}\right)^{3}+b\left(\frac{\dot{V}}{\dot{V}_{d}}\right)^{2}+c \frac{\dot{V}}{\dot{V}_{d}}+d
$$

with constants a, b, c and d equal to $-0.168,-0.0336,0.6317$ and 0.5699 . Estimation of the turbine isentropic efficiency was based on the work on axial steam turbines by Schobeiri [37]. Manente et al. [38] recently applied a very similar approach in a model of a large scale geothermal ORC power station. The relative isentropic efficiency at any load is defined as follows:

$$
\frac{\eta_{s}}{\eta_{s, d}}=\frac{N}{N_{d}} \sqrt{\frac{\Delta h_{s, d}}{\Delta h_{s}}}\left(2-\frac{N}{N_{d}} \sqrt{\frac{\Delta h_{s, d}}{\Delta h_{s}}}\right)
$$

where $h$ is enthalpy, and the subscripts $s$ and $d$ are short for isentropic and design point. $\Delta$ symbolises the difference between inlet and outlet. The relationship between expander pressures, temperatures and mass flow rates is governed by the law of the ellipse by Stodola [31] (Eq. 1).

The overall design point UA values $\left(\bar{U} A_{d}\right)$ for each heat exchanger were determined by dividing the heat flow rate with the logarithmic mean temperature. At part-load conditions the UA values correlate with the mass flow rates as follows:

$$
\bar{U} A=\bar{U} A_{d}\left(\frac{\dot{m}}{\dot{m}_{d}}\right)^{m}
$$

where $\bar{U}$ is the overall heat transfer coefficient and $A$ is the heat transfer area. It was assumed that a once-through boiler is to be applied and that the heat transfer is dominated by the gas flow 


\begin{tabular}{rrrrr}
\hline Engine speed (\%) & 100 & 91 & 80 & 63 \\
Brake power (\%) & 100 & 75 & 50 & 25 \\
Weighting factor (-) & 0.2 & 0.5 & 0.15 & 0.15 \\
\hline
\end{tabular}

on the outside of the tubes. Therefore, a value of 0.6 was selected for the exponent $m$ in reference to Incropera et al. [39].

Haglind [40] presented, for the application on board large ships, an expression for the generator part-load efficiency $\left(\eta_{e}\right)$ as a function of the load $(l)$, the design point efficiency $\left(\eta_{d, e}\right)$ and the copper loss fraction $\left(F_{c u}\right)$, which was adjusted to 0.43 to match manufacturer data:

$$
\eta_{e}=\frac{l \eta_{d, e}}{l \eta_{d, e}+\left(1-\eta_{d, e}\right)\left[\left(1-F_{c u}\right)+F_{c u} l^{2}\right]}
$$

Based on the review of Bao et al. [41] and on previous work [42], the selection of working fluids for investigation include R245fa, R365mfc, R236ea, hexamethyldisiloxane, isohexane, cyclopentane, toluene and benzene.

\subsection{Optimisation}

To perform the optimisation a genetic algorithm function (gamultiobj) from the Matlab [43] optimtool toolbox was used. The algorithm optimises both the NOx and the SFOC simultaneously forming a Pareto front, which is a line of optimum solutions, where at any point the value of one objective cannot be reduced without increasing the value of the other [46]. This algorithm was chosen because it is particularly suitable for optimisation in cases with many parameters and in cases where a global minimum might not be located due to the presence of local minima. The default parameters [43] were used for the gamultiobj function, except for the number of generations which was set to 50-100 and the number of individuals was set to 4,000-15,000 depending on how easily the algorithm seemed to be able to find the optima. These values were found to provide a reasonable compromise between repeatability of the optimisation results and computational cost, which is important considering the time consumption of the optimisations was between 3-21 days per result, using a machine with a 64-bit quad-core i7 $3.2 \mathrm{Ghz}$ processor.

Table 3 presents the optimisation parameters and their boundaries, which were chosen wide enough to ensure that the optima would not be limited by the parameter variation limits. The 
start of injection time (SOI), end of injection time, exhaust valve closing time (EVC), scavenge pressure $\left(P_{s c}\right)$ and fuel mass flow rates $\left(\dot{m}_{f}\right)$ were optimised independently for each load $(25,50,75$ and $100 \%)$. The air mass flow rates $\left(\dot{m}_{a}\right)$ were optimised only at design point, i.e., $100 \%$ load and at $25 \%$ in cases with an auxiliary blower. The mass flow rates at 75 and $50 \%$ load were determined by the pressure and the compressor operating line. $P_{c r}$ is short for the fluid critical pressure, and $\Delta T_{p p}$ is the minimum pinch point temperature difference.

\begin{tabular}{rr} 
Table 3: Optimisation parameters and limits \\
\hline & Limits \\
\hline Start of injection (CAD) & \pm 5 \\
End of injection (CAD) & \pm 10 \\
Exhaust valve closing (CAD) & \pm 10 \\
Scavenge pressure (\%) & \pm 10 \\
Fuel mass flow rate (\%) & \pm 10 \\
Air mass flow rate $(\%)$ & \pm 10 \\
ORC boiler $\Delta T_{p p}\left({ }^{\circ} \mathrm{C}\right)$ & $10-100$ \\
ORC recuperator $\Delta T_{p p}\left({ }^{\circ} \mathrm{C}\right)$ & $10-75$ \\
ORC evaporation pressure $(\mathrm{bar})$ & $3-0.95 P_{c r}$ \\
\hline
\end{tabular}

The part-load performance of the ORC depends on the applied control strategy; in the present case a sliding-pressure mode was adopted. The part-load evaporation pressures are thus governed by the Stodola equation (Eq. 1), by the heat transfer processes and by the pump characteristic curve. The latter component is here equipped with a variable frequency motor. This feature allows to investigate different operational modes, for example, keeping the turbine inlet temperature constant; however, results suggested that keeping the boiler exhaust gas outlet temperature constant, at the minimum allowed temperature $\left(160^{\circ} \mathrm{C}\right)$, lead to the highest combined cycle work outputs. In addition, an advantage of applying this strategy is that it ensures that sulphuric acid condensation in the heat exchangers is effectively prevented, particularly at low loads.

The optimisation algorithm was furthermore programmed to discard solutions which violate a minimum temperature approach of $10^{\circ} \mathrm{C}$, between the outlet of the recuperator and the boiling temperature, to prevent evaporation in the preheater.

It was decided to disable the ORC at $25 \%$ load because it was found that the combined cycle plant could be optimised to perform better overall, when only operating at 50-100\% loads. This is partly due to the required ORC boiler exhaust outlet temperature, creating a low temperature 
difference between the heat source inlet and outlet at low loads. Another reason is that the IMO weighting factors strongly favour the performance at $75 \%$ load (see Table 2).

For the type of system under study, the engine crank shaft is directly coupled to the propeller shaft, i.e., the engine turns at the same speed as the propeller. The IMO rules specify that for the evaluation of the SFOC and NOx, the engine has to operate under the constraint of the propeller law, which states that the engine brake power divided by the engine revolutions (rpm) to the power of three, must be constant [44]. This constant is related to the characteristics and working conditions of the propeller, and this relationship was respected at all loads, using the value of the constant calculated at standard tuning conditions. Hence, the propeller law poses an important constraint for the optimisation of the engine operational parameters. A one percent tolerance was allowed in order to facilitate the convergence of the optimisation, a value corresponding to the measurement inaccuracy allowed by the IMO [45].

The sequence of running the models during optimisation was as follows: first the engine with turbochargers was simulated at loads 100, 75, 50 and 25\%. Then the ORC was simulated at design point to determine the design point power, UA values, turbine constant and other outputs. Then, the ORC was simulated at part-loads 75 and 50\%. Finally, the propeller constant was calculated, and the deviation from the standard tuning value, was used as a factor to increase the values of the SFOC and the NOx. This way the optimisation algorithm simultaneously optimised the system parameters and minimised the deviation from the propeller law.

\subsection{Modelling conditions}

Table 4 lists the modelling boundary conditions. The pressure rise is the difference between the compression pressure and the maximum pressure, and a value corresponding to the reference tuning of the engine was selected, to have the same level of resulting mechanical stresses [47]. However, to enable the investigation of the optimum maximum cylinder pressures, no upper limit was specified.

\section{Engine model validation}

Figure 4 presents the predicted performance of the 7L70MC engine against the available data. The error bars indicate the $\pm 15 \%$ tolerance on the exhaust temperature and $\pm 5 \%$ tolerance on the SFOC, specified by the manufacturer. The model is in good agreement with the data from 
Table 4: Modelling conditions

\begin{tabular}{rr}
\hline \multicolumn{3}{c}{ Organic Rankine cycle } \\
\hline Pump design point efficiency (\%) & 72 \\
Turbine design point efficiency (\%) & 80 \\
Generator design point efficiency (\%) & 98 \\
Condenser outlet temperature $\left({ }^{\circ} \mathrm{C}\right)$ & 30 \\
\hline Diesel engine \\
\hline Ambient pressure (bar) & 1.013 \\
\hline Cooling water temperature $\left({ }^{\circ} \mathrm{C}\right)$ & 25 \\
Minimum exhaust temperature $\left({ }^{\circ} \mathrm{C}\right)$ & 160 \\
Allowed pressure rise (bar) & 30 \\
Blower efficiencies $(-)$ & 0.70 \\
\hline
\end{tabular}

Goldsworthy, with the largest discrepancies on the NOx emissions. However, the IMO weighted NOx is found to be similar to the Goldsworthy data with $17 \mathrm{~g} / \mathrm{kWh}$.

The $12 \mathrm{~K} 98 \mathrm{ME}$ engine presents a more interesting case study, mainly because it is larger and it is electronically controlled with more potential for tuning, compared to the 7L70MC engine.

Figure 5 presents the experimental and the modelled relative heat release over the engine revolution in crank angle degrees $(\mathrm{CAD})$ after bottom dead center (ABDC); it is evident that the double Wiebe heat release function can be adjusted to provide a very realistic heat release in this case. The resulting pressure curves for the engine cycle match very well, as shown in Fig. 6. Figure 7 presents the performance according to the model and to data provided by the manufacturer.

No data regarding the NOx emissions for the same engine type and operating conditions were found; however, the engine is certified for IMO Tier I level NOx $(17 \mathrm{~g} / \mathrm{kWh})$. Egeberg et al. [48] presented figures of NOx emissions for the mechanically controlled counterpart, the 12K98MC type, for which the IMO weighted NOx is $14.3 \mathrm{~g} / \mathrm{kWh}$. The predicted NOx in Fig. 7 averages to $14.9 \mathrm{~g} / \mathrm{kWh}$.

Table 5 presents the model prediction root-mean-square deviations from the experimental data (see Figs. 4 and 7). Large deviations are seen for the cooling load, particularly in the 12K98ME case. The SFOC prediction deviation for the $12 \mathrm{~K} 98 \mathrm{ME}$ engine is also significant, but it is within the mentioned tolerance of $5 \%$ and the SFOC trend across loads is correctly predicted. 


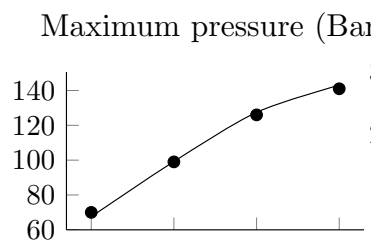

Power $(\mathrm{kW} /$ cylinder $)$

Cooling ( $\mathrm{kW} /$ cylinder)
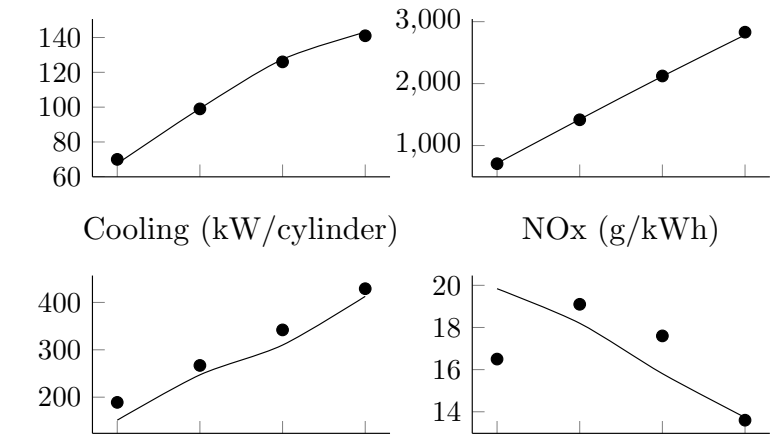

NOx $(\mathrm{g} / \mathrm{kWh})$

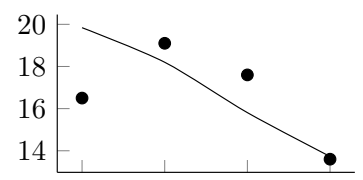

Exhaust temperature $\left({ }^{\circ} \mathrm{C}\right)$

$\operatorname{SFOC}(\mathrm{g} / \mathrm{kWh})$
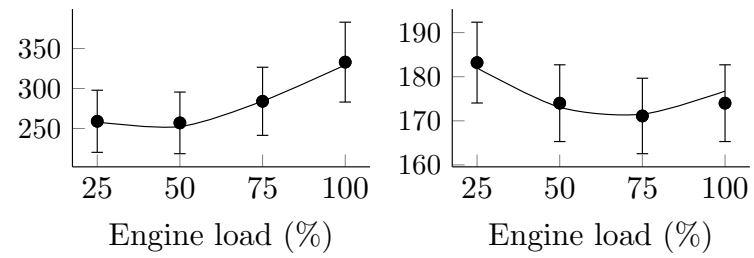

7L70MC Model • Goldsworthy

Figure 4: 7L70MC model and experimental values for main performance parameters.

The NOx prediction deviations are significant for the 7L70MC engine (see Fig. 4); though Kjemtrup et al. [49], who reviewed emissions modelling, concluded that exact predictions cannot be expected from the present type of model. Moreover, Kilpinin [24] concluded that the present NOx model needs further development and validation to be able to make absolute predictions, while trends can be predicted well.

The exhaust temperatures, which are particularly important for the present WHR systems analysis, are predicted with root-mean-square deviations of about $1 \%$.

\begin{tabular}{rrr} 
Table 5: Prediction root-mean-square deviation \\
\hline & 7L70MC & 12K98ME \\
\hline Maximum pressure (\%) & 2.0 & 0.5 \\
Power (\%) & 0.9 & 0.8 \\
Cooling (\%) & 11.8 & 37.3 \\
Exhaust temperature (\%) & 1.1 & 1.0 \\
NOx (\%) & 11.6 & N/A \\
SFOC (\%) & 0.9 & 4.0 \\
\hline
\end{tabular}


$100 \% \mathrm{MCR}$
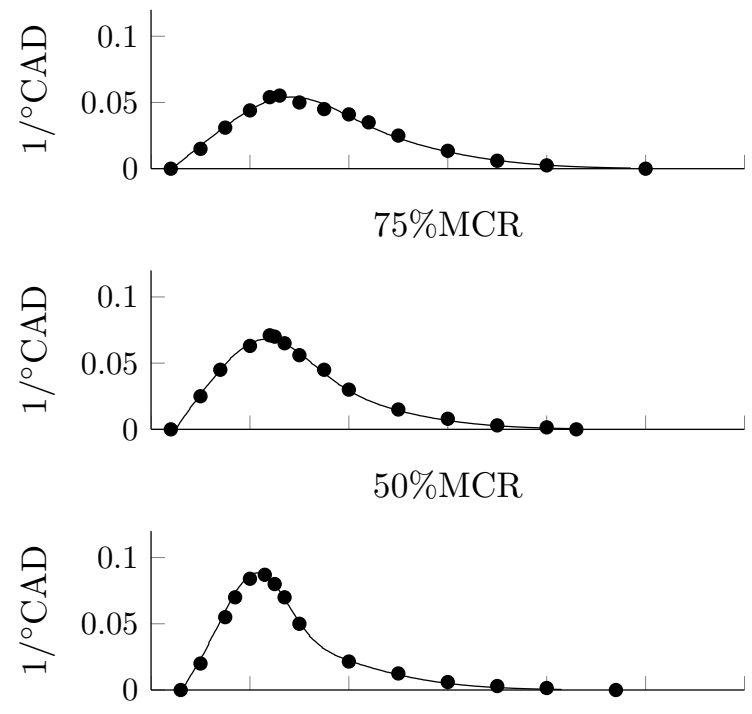

$25 \% \mathrm{MCR}$

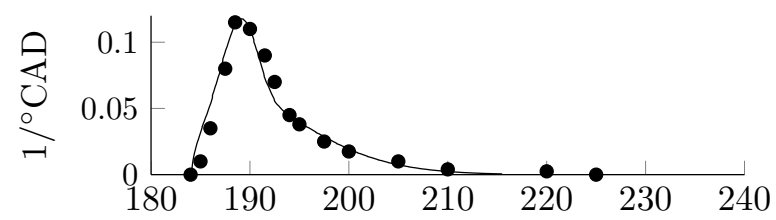

$\mathrm{CAD},{ }^{\circ} \mathrm{ABDC}$

- Measurements — 12K98ME Model

Figure 5: Predicted and experimental relative heat release per CAD for the $12 \mathrm{~K} 98 \mathrm{ME}$ engine.

\subsection{Model development}

As mentioned, the engine model was further developed after the initial validation [12]. The changes were made to improve the ability of the model to predict absolute values. It was investigated if the model is still able to predict the relative NOX and SFOC trends. With all other parameters kept constant, the parameters were varied as described in Scappin et al. [12], i.e., the compression pressure $\left(P_{c}\right)$ was varied 10 bar while keeping the maximum pressure $\left(P_{m}\right)$ constant, the maximum pressure was varied 10 bar while keeping the compression pressure constant and the scavenge pressure was varied from 2.9 to 3.1 bar while keeping the compression and maximum pressures constant. The variations were made using the timing of the exhaust valve closing, and start and end of injection [12].

The main results of the investigation are shown in Table 6 . The largest deviation is about $0.3 \%$ 

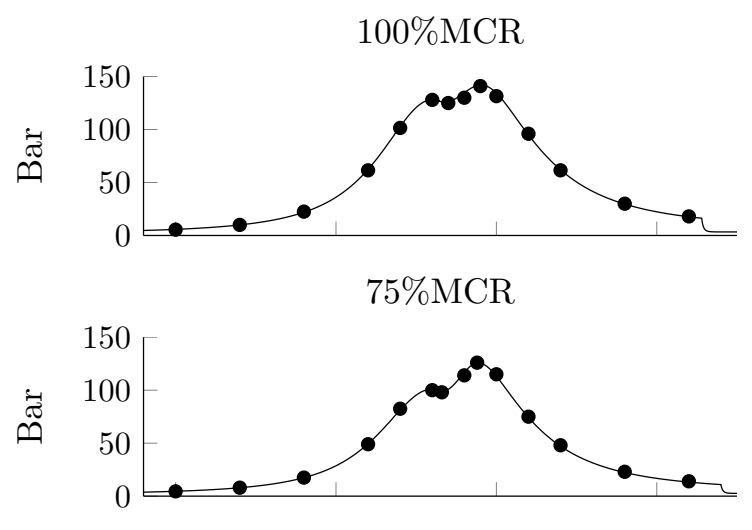

$50 \% \mathrm{MCR}$
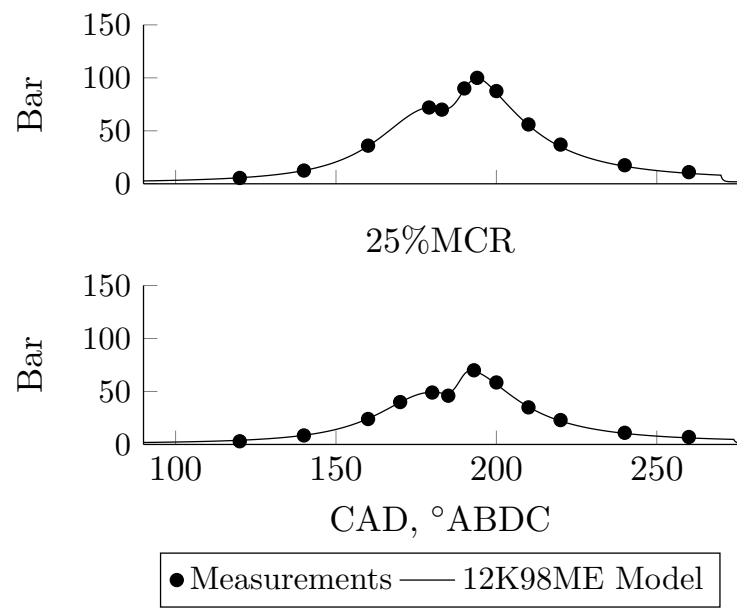

Figure 6: Predicted and measured 12K98ME cylinder pressures.

for the NOx emissions when assuming ideal gas conditions. A similar deviation of about $0.3 \%$ was found for the SFOC when assuming that no friction exists. All deviations are less than $0.34 \%$ and seem insignificant in comparison with the expected accuracy for this type of model.

\subsection{Exhaust gas recirculation}

Available measurements of the effects of EGR on the marine two-stroke engine are limited and more so the specific conditions of the measurements. Fig. 8 presents model results and measured data from initial tests of a MAN two-stroke engine fitted with EGR [50]. The 12K98ME model was run at $75 \%$ load, and the only parameter varied to obtain the shown results was the EGR ratio, defined as the recirculated mass flow rate divided by the total inlet mass flow rate.

While results shown in the figure do not validate the model regarding the ability to predict 
Maximum pressure (Bar) Power $(\mathrm{kW} /$ cylinder $)$
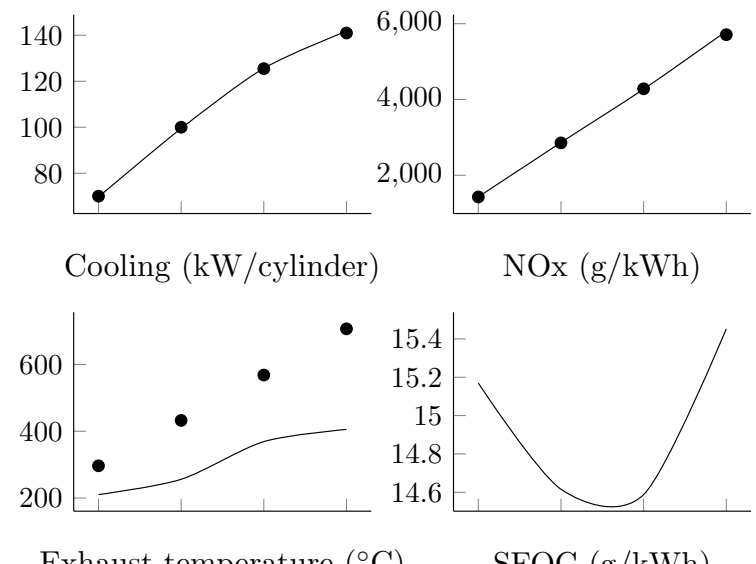

Exhaust temperature $\left({ }^{\circ} \mathrm{C}\right) \quad$ SFOC $(\mathrm{g} / \mathrm{kWh})$

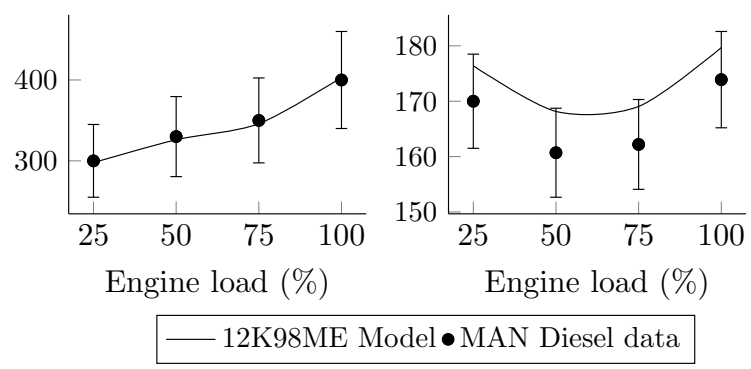

Figure 7: 12K98ME model and experimental values for main performance parameters.

effects of EGR, they suggest good qualitative agreement between model and measurements. The model over-estimates the NOx reduction at high EGR rates and under-estimates the SFOC increase. A similar over-estimation trend was found by Yamamoto et al. [51] and also by Kim et al. [52].

An explanation for the NOx under-estimation could be that the applied NO formation reactions (Zeldovich and $\mathrm{N} 2 \mathrm{O}$ schemes) are not entirely adequate when using high amounts of EGR. The simplified combustion model may also play an important role. Regarding the SFOC predictions, the experimental results in Fig. 8 were presented with limited specific information [50], i.e., the

Table 6: Maximum deviations in response trends

\begin{tabular}{rcccccc}
\hline & \multicolumn{2}{c}{ Varied $P_{c}(\%)$} & \multicolumn{2}{c}{ Varied $P_{m}(\%)$} & \multicolumn{2}{c}{ Varied $p_{s c}(\%)$} \\
\hline & NOx & SFOC & NOx & SFOC & NOx & SFOC \\
\hline Ideal gas & 0.34 & 0.06 & 0.27 & 0.12 & 0.05 & 0.06 \\
No friction & 0.13 & 0.12 & 0.23 & 0.28 & 0.07 & 0.07 \\
No N2O & 0.20 & 0.06 & 0.02 & 0.02 & 0.01 & 0.04 \\
\hline
\end{tabular}




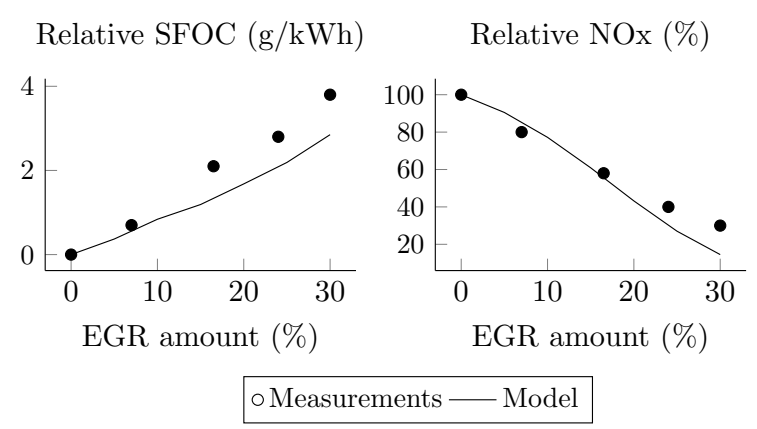

Figure 8: Comparison of EGR effect on SFOC and NOx

engine model type is not specified. Moreover, a range of engine tuning parameters can influence the results; e.g., it is unknown whether or not the maximum pressure is kept constant at all EGR amounts by adjusting the operation parameters.

The applied NO formation mechanisms have been proven thoroughly in the literature under a large variation of circumstances, including EGR. The model NO formation depends on the temperature, pressure and concentration of species at any given time. It can therefore be assumed that the ability to predict EGR effects otherwise relates to the ability to predict the conditions in the cylinder, especially during the combustion event.

\section{Results}

\subsection{Optimisation results}

Figure 9 presents the main optimisation results. Compared to the baseline case, i.e., tuning of the main engine (ME), the results suggest that the use of a power turbine (ME, PT) can lead to $3-4 \%$ SFOC and NOx reductions.

With the ORC WHR system (ME, ORC), calculations suggest that a 6\% SFOC reduction can be achieved, compared to the baseline case, while the NOx emissions can be reduced to a lesser degree. The ORC and hybrid T/Cs layout (ME, HTC, ORC) may lead to SFOC reductions of around $8 \%$ compared to the baseline, while the NOx is generally higher compared to the layouts using a power turbine and an ORC.

The results for the system layouts with an ORC, shown in Fig. 9, are based on an ORC utilising isohexane as the working fluid, with an evaporation pressure of about 17-18 bar, boiler pinch point 


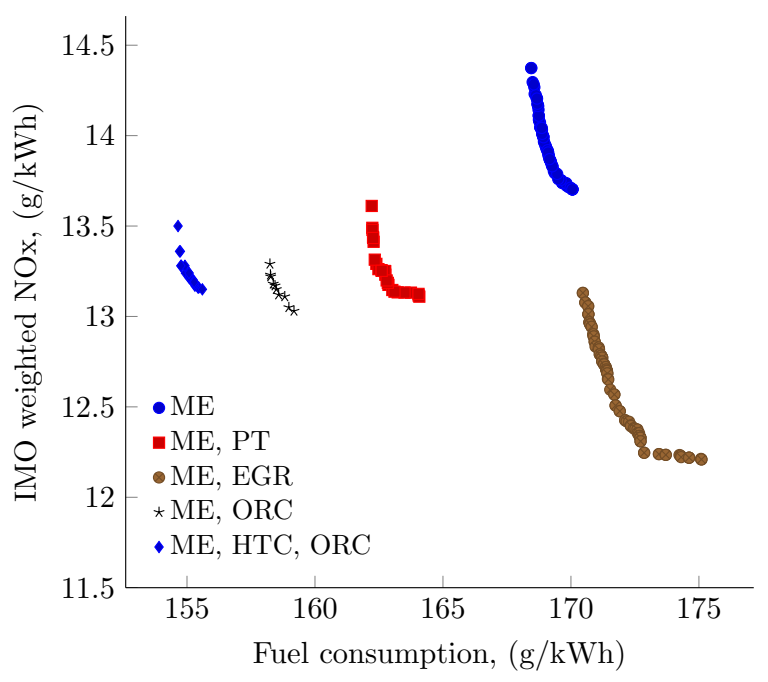

Figure 9: Fuel consumption and NOx trade-off

temperature differences of about $15-25^{\circ} \mathrm{C}$ and recuperator pinch point temperature differences of $20-30^{\circ} \mathrm{C}$.

With the use of 10\% EGR (ME, EGR), the results suggest that the SFOC increases a few percent, but the NOx is reduced by about 10\%. Moreover, the use of $10 \%$ EGR can lead to NOx reductions, while maintaining the SFOC at the same level as the baseline case when tuned to the minimum NOx emissions.

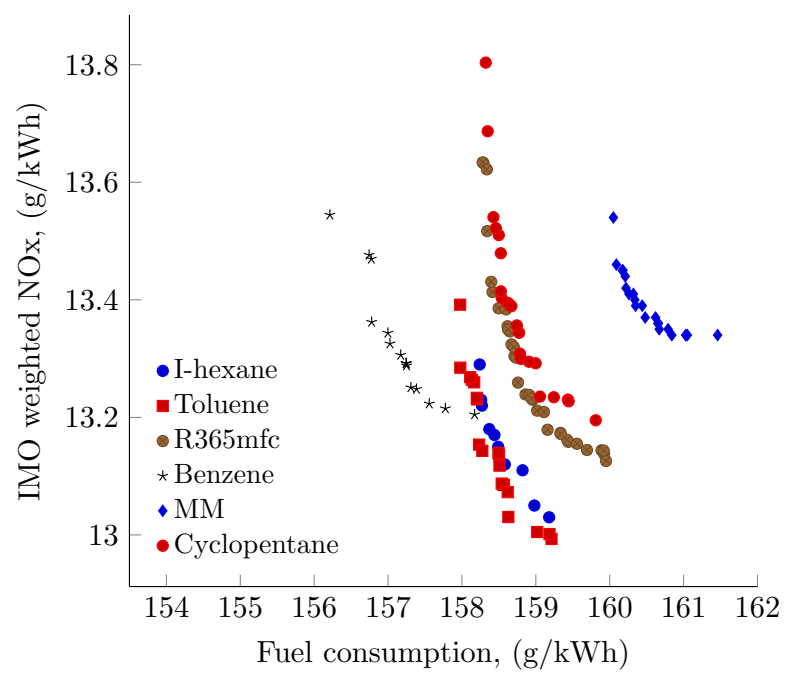

Figure 10: Fuel consumption and NOx trade-off for using the main engine and ORC layout 


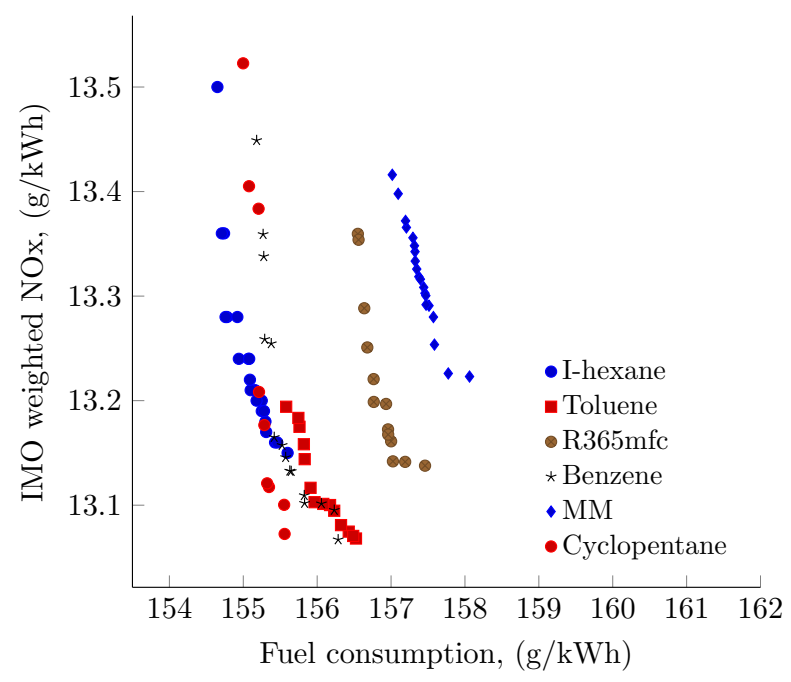

Figure 11: Fuel consumption and NOx trade-off for using the main engine and HTC-ORC layout

Figures 10 and 11 present the optimised trade-offs for six ORC working fluid options. The results suggest that using benzene, isohexane, cyclopentane and toluene may lead to the largest reductions. With the use of R245fa in the ME, HTC, ORC system, the results suggest that the SFOC-NOx trade-off is comparable to that of the ME, PT system. Simulations using R236ea provided no useful results in either system due to too low evaporation temperatures, leading to thermodynamic inconsistencies in the part-load calculations.

Table 7: Main engine performance parameters relative to the reference $(75 \%$ load)

\begin{tabular}{rrrrrrrrrrrrrrrrrr}
\hline & \multicolumn{1}{c}{$P_{c}(\%)$} & \multicolumn{2}{c}{$P_{m}(\%)$} & \multicolumn{2}{c}{$T_{e}(\%)$} & \multicolumn{2}{c}{$\dot{m}_{e}(\%)$} & & \multicolumn{2}{c}{$T_{w}(\%)$} & & \multicolumn{2}{c}{ NOx $(\%)$} & SFOC $(\%)$ \\
\hline Tuning & SFOC & NOx & SFOC & NOx & SFOC & NOx & SFOC & NOx & SFOC & NOx & SFOC & NOx & SFOC & NOx \\
\hline ME & -7 & -2 & -2 & 1 & -5 & -7 & 14 & 14 & -16 & -19 & -3 & -10 & -3 & -2 \\
PT & -8 & -4 & -6 & -3 & 21 & 16 & -9 & -4 & 23 & 16 & -2 & -9 & 0 & 0 \\
EGR & 0 & 1 & 3 & -6 & -5 & -4 & 8 & 10 & -11 & -10 & -12 & -20 & -2 & 1 \\
ORC & -11 & -12 & -13 & -15 & 26 & 26 & -10 & -10 & 32 & 33 & -1 & -2 & 2 & 3 \\
HTC, ORC & -11 & -10 & -13 & -14 & 26 & 25 & -10 & -9 & 32 & 31 & 1 & -3 & 2 & 2 \\
\hline
\end{tabular}

Table 7 presents the optimised engine performance parameters at $75 \%$ load, relative to the parameters leading to the validation results (see Sec. 2.5). Relatively low compression pressures lead to the best performance, with the exception of the EGR case. With low compression pressures, less work is needed for the compression stroke [53] which in this case contributes to lower NOx and SFOC. The maximum pressure is not reduced as much in the ME case, and this illustrates the importance of the pressure rise $\left(P_{m}-P_{c}\right)$ for the engine efficiency. In the cases with $\mathrm{PT}$ and 
ORCs, the maximum cylinder pressures are reduced. In the ORC cases this is the cause of the increased (main engine) SFOC and the reduction in NOx. However, reduced engine efficiencies contribute to increased exhaust temperatures $\left(T_{e}\right)$ and thus higher WHR inlet temperatures $\left(T_{w}\right)$, thereby increasing the performance of the ORC systems. The same cases exhibit reductions in the exhaust mass flow rates $\left(\dot{m}_{e}\right)$, which also result in higher exhaust WHR inlet temperatures.

\begin{tabular}{|c|c|c|c|c|c|c|c|c|c|c|}
\hline \multirow[b]{2}{*}{ Objective } & \multicolumn{2}{|c|}{ SOI (CAD) } & \multicolumn{2}{|c|}{ EOI (CAD) } & \multicolumn{2}{|c|}{$\mathrm{EVC}(\mathrm{CAD})$} & \multicolumn{2}{|c|}{$P_{s c}(\%)$} & \multicolumn{2}{|c|}{$\dot{m}_{f}(\%)$} \\
\hline & SFOC & NOx & SFOC & NOx & SFOC & NOx & SFOC & NOx & SFOC & NOx \\
\hline $\mathrm{ME}$ & -0.4 & -2.1 & -1.0 & 6.5 & 8.3 & 6.0 & 4.0 & 5.3 & -2.0 & -1.6 \\
\hline $\mathrm{PT}$ & -0.1 & -1.6 & 2.8 & 9.2 & 6.4 & 6.0 & 0.1 & 3.3 & 0.2 & 0.4 \\
\hline EGR & 0.2 & 1.4 & -5.8 & 3.2 & 5.0 & 4.6 & 6.8 & 6.2 & -2.3 & -0.1 \\
\hline ORC & 1.2 & 1.3 & 4.6 & 6.8 & 7.0 & 6.3 & -2.5 & -4.5 & 2.0 & 3.2 \\
\hline HTC, ORC & 1.7 & 1.5 & 3.1 & 6.4 & 7.1 & 7.1 & -2.1 & -0.8 & 1.9 & 1.8 \\
\hline
\end{tabular}

Table 8 presents the engine operating parameters relative to the standard tuning at $75 \%$ load that lead to the results in Tab. 7. The lowering of the compression pressures is caused by increased EVC timings, and in the case with the ORCs, also reduced scavenge pressures. The increased exhaust temperatures in the cases with the ORC are also caused by increased fuel flow rates. In the cases with the ORC and the PT, the EOIs are retarded to reduce the maximum pressures. There is a clear trend in all cases towards retarding the EOI when the objective is to minimise the NOx.

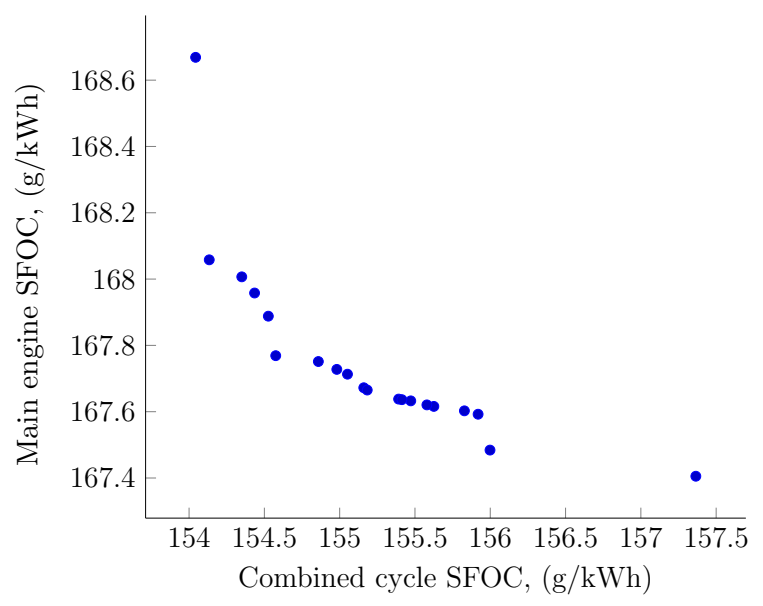

Figure 12: Optimised trade-off between main engine SFOC and ME, HTC, ORC layout. 
Figure 12 presents optimised cases using the ME, HTC, ORC system with cyclopentane. The results suggest that increasing the main engine SFOC with about $0.5-1 \mathrm{~g} / \mathrm{kWh}$ (by engine tuning), may lead to combined cycle fuel savings of up to $3.5 \mathrm{~g} / \mathrm{kWh}$.

\subsection{Economical comparison}

For economical comparison, the component purchase costs for each WHR system were estimated and used to predict the net present values (NPV). The power turbine cost was estimated using a number provided by MAN diesel [3]; the ORC module costs were derived from Quillon et al. [54], and the generator costs from Lian et al. [55].

The estimated total purchase costs are $2.13,8.25$ and 8.64 million US $\$$ for the ME, PT, the ME, ORC and the ME, HTC, ORC systems. With a fuel price of 483 US\$/ton [56] and optimised average fuel consumptions of $162.0,158.5$ and $155.0 \mathrm{~g} / \mathrm{kWh}$, for the same three systems, the yearly fuel savings are 0.94, 1.49 and 2.04 million US\$/year. It is here assumed that the operation occurs as according to the IMO weighting factors (see Table 2) with an average operational time of $65 \%$ (an assumption which is based on discussions with colleagues in the industry).

Assuming an interest rate of 10\%/year, the NPVs become positive after 2.5, 8.5 and 5.8 years for the ME, PT, the ME, ORC and the ME, HTC, ORC systems. The NPVs considering a 20 years ship life time [56] are 5.9, 4.5 and 8.8 million US\$.

\section{Discussion}

As may be expected, the combined cycle fuel efficiencies of the investigated system layouts increase with increasing system complexity while the NOx generally decreases. The simple power turbine configuration presents notable potentials with about 4\% SFOC and NOx reductions, which matches engine manufacturer information [3]. The main reason is that the power turbine utilises the pressure component of the exhaust gas waste energy [57]. With a system layout consisting of the hybrid turbines and the ORC, significantly lower SFOC and NOx emissions can be achieved, comparable in size to what a manufacturer presents for a system layout with a power turbine and an advanced dual-pressure steam cycle, which utilises the heat from the engine jacket water cooler and the charge air cooler [3].

Choi et al. [5] investigated the potential of a steam and ORC dual-cycle WHR system for the mechanically controlled $12 \mathrm{~K} 98 \mathrm{MC}$ engine. Using a different methodology, a similar potential of 
$6 \%$ SFOC reduction for a system without a power turbine was found.

The consideration of part-load performance influences the design and operating parameters of the main engine and WHR system significantly. For example, when considering design point optimisation only, as was recently done by the present authors [42], the ORC boiler temperature pinch points can be set relatively small, e.g., $10^{\circ} \mathrm{C}$. However, a conclusion that can be drawn from the investigations using the present methodology is, that such small pinch points at design point generally lead to pinch point violations and infinitely small superheating approaches at part-load conditions. This emphasises the importance of considering part-load performance of the presently studied type of systems, especially since the ships operate at part-load most of the time [58].

The optimised main engine tuning is markedly influenced by the system layout and this suggests that the investigation of the combined cycle efficiency must include engine tuning, an approach recently applied also by Srinivasan et al. [59].

For the application on board ships, it is an advantage that the ORC working fluid is not very hazardous, because safety is a major concern in the machinery rooms. For this reason refrigerant fluids that have low hazard levels may be preferred. However, none of the tested refrigerants performed well (R245fa and R236ea), except R365mfc which is highly flammable. All the hydrocarbon fluids have high fire hazard levels [42] creating an important drawback as their use requires additional safety precautions compared to using a steam Rankine cycle.

The economical comparison suggests that the ME, ORC system may, in a ship life time, not present a higher NPV than the simpler ME, PT configuration. Moreover, the ME, HTC, ORC configuration NPV becomes larger than the ME, PT system only after about 9.5 years. It is noted that these results are averaged estimates under assumptions that are uncertain, for example due to ever changing fuel prices or slow-steaming operation. Moreover, additional expenses related to installation and maintenance must be added. Still, the numbers are in good agreement with numbers presented by the industry for similar systems [56].

\section{Conclusion}

Methodologies useful for the investigation of five different system layouts with regards to their SFOC-NOx trade-offs were presented. Model results suggest that increased system complexity can result in lower SFOC and NOx. The use of an exhaust gas power turbine may lead to reductions 
in fuel consumption and NOx of about 3-4\% compared the stand-alone engine. With the isohexane ORC WHR system, reductions of about $6 \%$ may be achieved and with the addition of a hybrid type turbocharger, SFOC and NOx reductions of about $8 \%$ can be reached. The use of $10 \%$ EGR may lead to about $10 \%$ lower NOx emissions with limited or no SFOC penalty. The results clearly suggest that the optimisation of the investigated combined cycles should be done taking into account the entire system at the same time. A simplified economical comparison suggests that the power turbine system is the more attractive system on the short term, while on the longer term the ME, HTC, ORC system shows the most potential.

\section{Acknowledgements}

The authors wish to thank Cecilia Gabrielii of the Chalmers University of Technology in Gothenburg, Sweden for her important comments and suggestions. MAN Diesel \& Turbo and ABB are hereby thanked for the contribution of experimental data. The Lighthouse Maritime Competence Centre (www.lighthouse.nu) is acknowledged for the financial support making this study possible. Susan Canali is thanked for her proof reading assistance. 


\section{References}

[1] Kaltoft J, Preem M. Development of integrated EGR system for two-stroke diesel engines. In: CIMAC International Council on Combustion engines 2013. Shanghai, China: CIMAC; 2013, p. 1-16.

[2] Haglind F. Variable geometry gas turbines for improving the part-load performance of marine combined cycles - Combined cycle performance. Applied Thermal Engineering 2011;31(4):467 -76. doi: dx.doi.org/10.1016/j.applthermaleng.2010.09.029.

[3] Diesel and Turbo M. Waste Heat Recovery System (WHRS) for Reduction of Fuel Consumption, Emissions and EEDI. Tech. Rep.; MAN Diesel and Turbo; Copenhagen, Denmark; 2011.

[4] Shu G, Liang Y, Wei H, Tian H, Zhao J, Liu L. A review of waste heat recovery on two-stroke IC engine aboard ships. Renewable and Sustainable Energy Reviews 2013;19(0):385 - $401 . \quad$ doi: dx.doi.org/10.1016/j.rser.2012.11.034.

[5] Choi BC, Kim YM. Thermodynamic analysis of a dual loop heat recovery system with trilateral cycle applied to exhaust gases of internal combustion engine for propulsion of the 6800 TEU container ship. Energy 2013;:doi: 10.1016/j.energy.2013.05.017.

[6] Theotokatos G, Livanos G. Techno-economical analysis of single pressure exhaust gas waste heat recovery systems in marine propulsion plants. Proceedings of the Institution of Mechanical Engineers Part M: Journal of Engineering for the Maritime Environment 2013;227(2):83-97. doi:10.1177/1475090212457894.

[7] Dimopoulos GG, Georgopoulou CA, Kakalis NM. Modelling and optimisation of an integrated marine combined cycle system. Novi sad, Serbia: Proceedings of ECOS 2011; 2011, p. 1283-98.

[8] Dimopoulos GG, Georgopoulou CA, Kakalis NM. The introduction of exergy analysis to the thermo-economic modelling and optimisation of a marine combined cycle system. Perugia, Italia: Proceedings of ECOS 2012; 2012 , p. $61-1-61-16$.

[9] Hountalas DT, Mavropoulos GC, Katsanos C. Efficiency Optimization of a 2-Stroke Diesel Engine Power Plant Through the Recovery of Exhaust Gas Using a Rankine Cycle. Perugia, Italia: Proceedings of ECOS 2012; 2012 , p. $404-1-404-17$.

[10] Guan C, Theotokatos G, Zhou P, Chen H. Computational investigation of a large containership propulsion engine operation at slow steaming conditions. Applied Energy 2014;130(0):370 -83. doi: dx.doi.org/10.1016/j.apenergy.2014.05.063.

[11] Yu G, Shu G, Tian H, Wei H, Liu L. Simulation and thermodynamic analysis of a bottoming organic rankine cycle (ORC) of diesel engine (DE). Energy 2013;51(0):281 -90. doi:dx.doi.org/10.1016/j.energy.2012.10.054.

[12] Scappin F, Stefansson SH, Haglind F, Andreasen A, Larsen U. Validation of a zero-dimensional model for prediction of NOx and engine performance for electronically controlled marine two-stroke diesel engines. Applied Thermal Engineering 2012;37(0):344 -52. doi:10.1016/j.applthermaleng.2011.11.047.

[13] Miyamoto N, Chikahisa T, Murayama T, Sawyer R. Description And Analysis Of Diesel Engine Rate Of Combustion And Performance Using Wiebe's Functions. Proceedings - Society of Automotive Engineers 1985;:77-88.

[14] Woschni G. A universally applicable equation for the instantaneous heat transfer coefficient in the internal combustion engine. SAE International 1967;doi:10.4271/670931. 
[15] Merker G. Simulating Combustion: Simulation of Combustion and Pollutant Formation for Engine-development. Springer; 2006. ISBN 9783540251613.

[16] Zevenhoven R. Non-ideal gases in diesel engine processes. Scandinavian Nordic Section Of The Combustion Institute Proceedings 2001;1:103-8.

[17] Lapuerta M, Ballesteros R, Agudelo JR. Effect of the gas state equation on the thermodynamic diagnostic of diesel combustion. Applied Thermal Engineering 2006;26(1415):1492 -9. doi: dx.doi.org/10.1016/j.applthermaleng.2006.01.001.

[18] Danov SN, Gupta AK. Influence of Imperfections in Working Media on Diesel Engine Indicator Process. Journal of Engineering for Gas Turbines and Power 2000;123(1):231-9. doi:dx.doi.org/10.1115/1.1339986.

[19] Poulsen HH. In-situ Investigations of the Combustion in Large, Two-stroke, Diesel Engines. Ph.D. thesis; Technical University of Denmark, Copenhagen Denmark; 2001.

[20] Heywood J. Internal combustion engine fundamentals. McGraw-Hill series in mechanical engineering; McGrawHill; 1988. ISBN 9780070286375.

[21] Chen SK, Flynn PF. Development of a single cylinder compression ignition research engine. 1965. doi: dx.doi.org/10.4271/650733.

[22] Horlock J, Winterbone D. The thermodynamics and gas dynamics of internal-combustion engines 1-2. Clarendon Press; 1982. ISBN 0198562101, 0198562128, 9780198562108, 9780198562122.

[23] Goldsworthy L. Reduced kinetics schemes for oxides of nitrogen emissions from a slow-speed marine diesel engine. Energy and Fuels 2003;17(2):450-6. doi:10.1021/ef020172c.

[24] Kilpinen P. Optimization of a simplified sub-model for NO emission prediction by CFD in large 4-stroke marine diesel engines. Fuel Processing Technology 2010;91(2):218-28. doi:10.1016/j.fuproc.2009.10.001.

[25] Larsen U, Sigthorsson O, Haglind F. A comparison of advanced heat recovery power cycles in a combined cycle for large ships. Energy 2014;74(0):260 -8. doi:dx.doi.org/10.1016/j.energy.2014.06.096. International Conference on Efficiency, Cost, Optimization, Simulation and Environmental Impact of Energy Systems ECOS 2013.

[26] Goldsworthy L. Real time model for oxides of nitrogen emissions from a slow speed marine diesel. Proceedings of IMarEST - Part A - Journal of Marine Engineering and Technology 2003;2003(2):3-12.

[27] Turbo D, MAN . CEAS-ERD: Engine Room Dimensioning Software. 2013. Accessed August 2013; URL wWw. mandieselturbo.com/ceas/index.html.

[28] Egnell R. On zero-dimensional modelling of combustion and NOx formation in diesel engines. Ph.D. thesis; Lund university, Sweden; 2001.

[29] Kurzke J. How to create a performance model of a gas turbine from a limited amount of information. Proceedings of the ASME Turbo Expo 2005;1:145-53. doi:10.1115/GT2005-68536.

[30] Heim K. Existing and Future Demands on the Turbocharging of Modern Large Two-stroke Diesel Engines. Tech. Rep.; Wartsila, Switzerland; Winterthur, Switzerland; 2002.

[31] Cooke DH. On Prediction Of Off-design Multistage Turbine Pressures By Stodolas Ellipse. Journal of Engineering for Gas Turbines and Power, Transactions of the ASME 1985;107(3):596-606.

[32] Lemmon E, Huber M, McLinden M. National Institute of Standards and Technology, Maryland, United States, Standard Reference Database 23 Reference Fluid Thermodynamic and Transport Properties-REFPROP, Soft- 
ware version 9.0. 2010 .

[33] Tochio S, Kondo M, Kunimitsu M, Ide R. Development of Large-Scale Turbocharger Generator Unit. In: CIMAC International Council on Combustion engines 2010. Bergen: CIMAC; 2010, p. 1-6.

[34] Ono Y. Solutions for better engine performance at low load by Mitsubishi turbochargers. In: CIMAC International Council on Combustion engines 2013. Shanghai: CIMAC; 2013, p. 1-6.

[35] Quoilin S, Aumann R, Grill A, Schuster A, Lemort V, Spliethoff H. Dynamic modeling and optimal control strategy of waste heat recovery Organic Rankine Cycles. Applied Energy 2011;88(6):2183-90.

[36] Manolakos D, Papadakis G, Papantonis D, Kyritsis S. A simulation-optimisation programme for designing hybrid energy systems for supplying electricity and fresh water through desalination to remote areas: Case study: the Merssini village, Donoussa island, Aegean Sea, Greece. Energy 2001;26(7):679 - 704 . doi: dx.doi.org/10.1016/S0360-5442(01)00026-3.

[37] Schobeiri M. Turbine aerodynamic design and off-design performance. In: Turbomachinery Flow Physics and Dynamic Performance. Springer Berlin Heidelberg. ISBN 978-3-540-22368-9; 2005, p. 409-37. doi:10.1007/9783-540-26591-7_17.

[38] Manente G, Toffolo A, Lazzaretto A, Paci M. An Organic Rankine Cycle off-design model for the search of the optimal control strategy. Energy 2013;58(0):97 - 106. doi:dx.doi.org/10.1016/j.energy.2012.12.035

[39] Incropera FP, DeWitt DP, Bergman TL, Lavine AS. Fundamentals of heat and mass transfer. Fundamentals of Heat and Mass Transfer; John Wiley; 2007. ISBN 9780471457282.

[40] Haglind F. Variable geometry gas turbines for improving the part-load performance of marine combined cycles gas turbine performance. Energy 2010;35(2):562 -70. doi:dx.doi.org/10.1016/j.energy.2009.10.026.

[41] Bao J, Zhao L. A review of working fluid and expander selections for organic Rankine cycle. Renewable and Sustainable Energy Reviews 2013;24(0):325 -42. doi:10.1016/j.rser.2013.03.040.

[42] Larsen U, Pierobon L, Haglind F, Gabrielii C. Design and optimisation of organic Rankine cycles for waste heat recovery in marine applications using the principles of natural selection. Energy 2013;(0):. doi: 10.1016/j.energy.2013.03.021.

[43] Mathworks Massachusetts US. Matlab R2013a. 2013.

[44] Diesel and Turbo M. Basic principles of ship propulsion. Tech. Rep.; MAN Diesel and Turbo; Copenhagen, Denmark; 2013.

[45] International Maritime Organization. IMO NOx technical code 2008. Tech. Rep.; IMO; London, United Kingdom; 2008. Accessed 21/01/2014; URL imo.org.

[46] Resources E. Website of Econlib Resources. 2014. Accessed 11/01/2014; URL econlib.org.

[47] Taylor C. The Internal-combustion Engine in Theory and Practice: Combustion, fuels, materials, design. The Internal-combustion Engine in Theory and Practice; M.I.T. Press; 1985. ISBN 9780262700276.

[48] Egeberg CE, Ostergaard A. The MC Engine And Its Future Development. In: CIMAC International Council on Combustion engines 2001. Hamburg, Germany: CIMAC; 2001, p. 7-27.

[49] Kjemtrup N, Aabo K, Knudsen TS. Developments on Exhaust Emission Modelling for Large Two-Stroke Diesel Engines Some Comparisons with Measured Data and an Update on the Latest Emission Reduction Techniques. In: CIMAC International Council on Combustion engines 2007. Vienna, Austria: CIMAC; 2007, p. 1-16. 
[50] Diesel, Turbo M. Exhaust Gas Emission Control Today and Tomorrow. Tech. Rep.; MAN Diesel and Turbo; Copenhagen, Denmark; 2010. Accessed 19/12/2013; URL mandieselturbo.com/.

[51] Yamamoto S, Nagaoka M, Ueda R, Wakisaka Y, Noda S. Numerical simulation of diesel combustion with a high exhaust gas recirculation rate. International Journal Of Engine Research 2010;11(1):17-27. doi: 10.1243/14680874JER05309.

[52] Kim SK, Wakisaka T, Aoyagi Y. A numerical study of the effects of boost pressure and exhaust gas recirculation ratio on the combustion process and exhaust emissions in a diesel engine. International Journal Of Engine Research 2007;8(2):147-62. doi:10.1243/14680874JER02606.

[53] Stiesh G, Merker GP. A Phenomenological Heat Release Model for Direct Injection Diesel Engines. In: CIMAC International Council on Combustion engines 1998. Copenhagen, Denmark: CIMAC; 1998, p. 1-8.

[54] Quoilin S, Broek MVD, Declaye S, Dewallef P, Lemort V. Techno-economic survey of Organic Rankine Cycle (ORC) systems. Renewable and Sustainable Energy Reviews 2013;22(0):168 -86. doi: dx.doi.org/10.1016/j.rser.2013.01.028.

[55] Lian Z, Chua K, Chou S. A thermoeconomic analysis of biomass energy for trigeneration. Applied Energy 2010;87(1):84 - 95. doi:dx.doi.org/10.1016/j.apenergy.2009.07.003.

[56] MAN Diesel \& Turbo, Denmark . Operation on Low-Sulphur Fuels. 2010. Accessed 05/09/2013; URL WWw. mandieselturbo.com.

[57] Woodward JB. Recovering The Energy In Diesel Exhaust: Some Thermodynamic Points. Marine Technology 1987;24(3):205-11.

[58] Gurgenci H. Performance of power plants with organic rankine cycles under part-load and off-design conditions. Solar energy 1986;36(1):45-51.

[59] Srinivasan KK, Mago PJ, Krishnan SR. Analysis of exhaust waste heat recovery from a dual fuel low temperature combustion engine using an Organic Rankine Cycle. Energy 2010;35(6):2387 -99. doi: dx.doi.org/10.1016/j.energy.2010.02.018. 